\title{
Algumas Notas mais sobre Ivanhoe no Romantismo Português (em torno de Alfredo Possolo Hogan - e com uma hipótese sobre o Frei Luís de Sousa de Garrett)
}

\author{
Jorge Bastos da Silva \\ Universidade do Porto - ILC
}

Resumo: Em estudos anteriores, procurámos demonstrar a especial relevância do romance de Walter Scott Ivanhoe (traduzido em 1837, 1838 e 1851) para a ficção histórica do Romantismo português, pondo em evidência o apreço que por essa narrativa tinham os nossos escritores de meados do século XIX e a circulação na sua escrita de motivos temáticos e diegéticos radicáveis naquela obra de Scott; e ocupámo-nos, por outro lado, de examinar o modo como a intriga de Ivanhoe foi levada à cena numa adaptação assinada por Alfredo Possolo Hogan em 1849, com significativas modulações de personagens, situações e temas. Retomando e aprofundando essas investigações, o presente artigo ensaiará cruzá-las, prestando atenção ao quadrilátero formado, no contexto do nosso Romantismo, por romance histórico original, romance histórico traduzido, drama histórico original e drama histórico traduzido.

Palavras-chave: Alfredo Possolo Hogan, Walter Scott, Ivanhoe, Almeida Garrett, Frei Luís de Sousa, Romantismo

Abstract: In previous studies I have sought to evince the specific relevance of Walter Scott's Ivanhoe (translated in 1837, 1838 and 1851) for the Portuguese historical novel of the Romantic Period, by highlighting the esteem in which that particular novel was held in the mid-1800s and the circulation in 
writings by Portuguese authors of thematic and narrative motifs that may have been derived therefrom; and I have additionally examined the ways in which Ivanhoe was adapted for the stage by Alfredo Possolo Hogan in 1849 , with significant modulations of characters, situations and themes. This article attempts to combine such earlier approaches by exploring the quadrilateral formed by original historical novel, translated historical novel, original historical drama and translated historical drama in the context of Portuguese Romanticism.

Keywords: Alfredo Possolo Hogan, Walter Scott, Ivanhoe, Almeida Garrett, Frei Luís de Sousa, Romanticism

\section{1.}

Num dos textos de Herculano citados com maior frequência por críticos e historiadores literários, o artigo “Gallicismos", vindo a lume n'O Panorama em Junho de 1837, lamenta essa reserva moral do liberalismo português - para quem tanto o liberalismo como a portugalidade eram valores inegociáveis - a dependência endémica da cultura lusa coeva face às influências da França:

A leitura frequente dos livros francezes tem corrompido a nossa linguagem por tal maneira, que já hoje é impossivel desinça-la dos gallicismos, nomeadamente os de phrase, em que abunda; se isto em alguns casos é damnoso ou util para a grammatica ideologica, isto é, se algumas construcções daquella lingua, extremamente regular, serão boas de ageitar ao nosso idioma, não o podemos aqui dizer; mas o que não padece duvida é que essa lição de auctores francezes poz em esquecimento os portuguezes; que os habitos e costumes excellentes dos nossos antepassados se tem alterado e modificado em grande maneira por tal motivo, visto que a frequencia de estrangeiros torna estranhos os usos de qualquer povo, e o tracto dos livros produz muitos effeitos semelhantes aos do tracto dos homens. $(O$ Panorama, I, n. 7 [17.6.1837], 52; também em Bastos da Silva 2015: 131)

O Romantismo literário português - à semelhança, aliás, de diversos outros Romantismos nacionais de Oitocentos - configura-se como um movimento sociocultural de combate em várias frentes, encontrando-se entre estas o projecto de restituir o povo português à plenitude da sua identidade, corrompida por sofrer aquele de uma estranheza 
de si mesmo que corresponde a uma sorte de degenerescência, e o ensejo de superação dos códigos estético-formais do Classicismo, superação ambicionada de modo consequente por um Herculano, em especial no domínio do romance histórico, prosseguida por via de sínteses conciliadoras ou de uma espécie de sincretismo do gosto no caso de Garrett e absolutamente tíbia em Castilho. Para muitos dos nossos intelectuais oitocentistas, esses dois grandes vectores, o que se prende com a identidade nacional e o que passa pela rejeição ou refundição das matrizes literárias neoclássicas, entrelaçam-se no propósito de se libertarem do francesismo prevalecente, que faria estiolar o génio natural dos criadores portugueses ou pelo menos lhe imprimiria um cunho que não lhe seria próprio - chegando Camilo, com a sua copiosa paleta de recursos expressivos, a pôr o Calisto Elói de $A$ Queda dum Anjo a declarar: "Eu não leio francês. Não me chega o meu tempo para tirar águas sujas de poços infectos" (Castelo Branco 1982-2002: V, 889-890). É certo que Calisto é um tolo, e que vem a sucumbir aos deslumbramentos de Paris, mas a caricatura deste galiparla (pois nisso se torna, à escala do seu provincianismo, o anjo caído) é uma forma particular de retratar um conjunto de lugares-comuns da época e não uma excentricidade camiliana.

Aproveitando palavras de Herculano, mas conferindo-lhes uma amplitude de significado apenas sugerida no artigo d'O Panorama, diríamos pois que os autores do nosso Romantismo - e para este efeito pouco importará diferenciar entre autores maiores e autores menores se essa destrinça atender apenas a critérios de apreciação do mérito estético - buscaram uma outra gramática ideológica que não a recebida de França, procurando-a na História de Portugal ou da Ibéria (o Herculano de Eurico ou de O Bobo é mais uma vez um bom exemplo), na tradição folclórica (como o Garrett do Romanceiro ou de Adozinda), e ensaiando também processos novos sob o influxo de leituras ou releituras do teatro espanhol (cujo impacto nos parece aguardar ainda cabal reconhecimento pelos estudiosos mas que é patente a quem compulse o periodismo da época), lendo ainda e sempre os gregos e latinos da Antiguidade, lendo, enfim, autores alemães e britânicos que escassamente haviam chegado até nós em períodos anteriores.

A renovação de práticas e referentes passou pela adopção de alternativas ao francesismo imperante, vindo a aproximação a aspectos seleccionados da cultura britânica 
- aquela que aqui mais nos interessa - a beneficiar do incremento de contactos proporcionado pela experiência do exílio imposto ou auto-imposto a duas gerações de liberais. Sem nunca deixar de ser dominantemente francocêntrico, e raras vezes o ocultando, o Romantismo literário português caldeou modelos que julgou úteis e profícuos - curiosamente, exibindo manifesto descaso (e só por prudência não dizemos que completo desconhecimento) pelos poetas que hoje aquilatamos de mais representativos do Romantismo de além-Mancha: Blake, Wordsworth, Coleridge, Shelley e Keats. ${ }^{1}$ Assim, o nosso Oitocentismo deixa-se seduzir pelos bardos da nacionalidade, como Macpherson, com os seus poemas ossiânicos, e Scott, o cantor da Escócia, cujo Waverley encontra tradução portuguesa por duas vezes em 1844 e de novo em 1845 (a densidade da ocorrência de versões é, obviamente, um dado fulcral); exalta Byron como encarnação do "herói romântico", que vive, ora heróica, ora desesperadamente, o ideal que a sua própria obra ajuda a construir como tipo, como pose, como maneira; admira Pope, presença paradoxal e surpreendente no registo de traduções e no discurso crítico e moral, que denota a persistência dos valores neoclássicos e iluministas; consagra Shakespeare, por longo tempo mais um nome que uma obra, e que talvez por isso dá para tudo: é um selvagem e é toda uma civilização, o criador mais espontâneo e o maior artista, homem do passado e epítome da modernidade, irredutivelmente inglês e supremamente universal, propagandista da monarquia absoluta e apóstolo da liberdade...

\section{2.}

Parafraseando um título do germanista José Gomes Monteiro, pode portanto dizer-se que os ecos da lira anglo-saxónica, mas também celta, se faziam ouvir repetida ainda que desencontradamente, e sobretudo que iam ganhando vulto ao longo de um século XIX que tem no alargamento dos horizontes culturais das Letras lusas uma das suas marcas distintivas. Neste contexto, parece-nos proveitoso regressar a incursões já realizadas que demonstram o relevo específico de Walter Scott como criador da novelística histórica estatuto amplamente reconhecido na época por Herculano, Rebelo da Silva e outros - com vista a reconsiderar o problema do seu impacto e do seu significado sob novos ângulos, 
mediante uma reapreciação da adaptação cénica de Ivanhoe elaborada por Alfredo Possolo Hogan em 1849 (cf. Bastos da Silva 2014; idem 2016). ${ }^{2}$

O Scott que assina Ivanhoe não é o escritor-cidadão ostensivamente preocupado em sondar as implicações éticas, políticas e sociais - e até sentimentais - do Jacobitismo que dá corpo a Waverley, propondo (com uma dose de melancolia, é certo) uma reconciliação pragmática de Ingleses e Escoceses, quando a monarquia hanoveriana se mostrava consolidada, os clãs do Norte estavam desarmados e até certo ponto desagregados, e era finda a linhagem dos Stuart com a morte do cardeal Henry Stuart em 1807. Ivanhoe será, por isso, uma narrativa falha de certo tipo de pitoresco etnográfico de timbre nacional - ou, se se preferir, de timbre regional. Mas de maneira alguma a tiveram os coevos em conta de narrativa falhada, já que a sua popularidade foi notória ${ }^{3}$ e aos leitores portugueses foram oferecidas nada menos que três traduções, em 1837, 1838 e 1851 . A crítica acolheu a obra com agrado, se não mesmo com entusiasmo, e é plausível que o surto do romance histórico entre nós seja em muito devedor dessa obra. Na escrita romanesca da época recorrem traços que coincidem com componentes temáticas e diegéticas de Ivanhoe: encontram-se torneios de cavalaria em $O$ Bobo de Herculano e em "A Noiva de Montemor" de José Freire de Serpa Pimentel, aparece um cavaleiro negro no Eurico de Herculano e em "A Torre de Cain" de Rebelo da Silva, há violência exercida sobre mulheres em "A Camisa do Noivado" de Rebelo da Silva e Os Tripeiros de Coelho Lousada. Mas os pontos de contacto revelam-se num plano que ultrapassa o das correspondências motívicas pontuais, discernindo-se mesmo uma grelha de relações manifesta no plano alargado da intriga. Como é sabido, Ivanhoe narra a história de um cavaleiro de estirpe saxónica que, a coberto da identidade de romeiro, regressa das Cruzadas, para onde seguira o rei Ricardo. Confrontado com os abusos perpetrados pelo alto clero e pela nobreza normanda, capitaneados pelo regente, o príncipe João, Ivanhoe vence num torneio os mais valentes cavaleiros normandos, entre eles o templário Brian de Bois-Guilbert, ficando gravemente ferido e recebendo os cuidados da judia Rebecca. Na sequência de peripécias que nos dispensamos de relatar, um misterioso cavaleiro negro revela a sua identidade: trata-se, afinal, do próprio rei Ricardo, que vem recompensar os que lhe foram fiéis, pôr fim à opressão, restaurar a justiça e 
instaurar a concórdia entre os súbditos, ficando a reinar sobre um povo que, em linguagem do nosso tempo (na nossa gramática ideológica), adjectivaríamos de multiétnico, multirreligioso e multicultural. 0 tema da reconciliação nacional presente em Waverley está assim presente também aqui, ainda que transposto para outro momento histórico e equacionado de acordo com linhas de cisão distintas.

A análise dos romances portugueses de meados da centúria indicia uma assimilação profunda da intriga e dos temas de Ivanhoe que se situa muito para além da simples reverberação de motivos esparsos. Essa assimilação sintetiza-se numa tópica composta pelos seguintes elementos principais: (1) uma circunstância histórica em que o povo é vítima de abusos por parte de nobres e clérigos, sendo a violação de mulheres uma expressão desses abusos e acrescendo ao conflito social uma mais vasta oposição interétnica e inter-religiosa; (2) sobre este pano de fundo, a luta do herói pela justiça, articulada com a causa de legitimidade política; (3) um soberano absentista mas que finalmente intervém com uma acção reparadora da ordem. Com modulações que todavia não põem em causa a integridade do padrão imaginativo, verifica-se a concretização deste esquema em $O$ Monge de Cister de Herculano, O Arco de Sant'Ana de Garrett e O Balio de Leça de Arnaldo Gama.

\section{3.}

A incidência da voga scottiana no caso particular de Ivanhoe assoma no drama de Alfredo Possolo Hogan, a cuja análise nos parece aproveitar um exercício crítico - sublinhe-se que apenas susceptível de ser esboçado aqui - que atente na circulação de topoi e dispositivos de composição ficcional (quer narrativa, quer dramática) dentro do quadrilátero formado, no contexto do nosso Romantismo, por romance histórico original, romance histórico traduzido, drama histórico original e drama histórico traduzido.

É nos meandros deste labirinto que pretendemos fazer uma curta viagem.

A peça de Hogan exibe características que vale a pena enunciar sucintamente. De forma muito selectiva, como é inevitável, dada a extensão do romance de Scott, reorganiza as componentes do entrecho em nove quadros, agrupados em cinco actos, ostentando cada 
quadro um título (com uma excepção, que pode ou não derivar de um lapso), como se do capítulo de um romance se tratasse. Nisto segue Hogan um procedimento consubstanciado em numerosos dramas históricos portugueses coetâneos, como $O$ Emparedado de A. M. de Sousa Lobo (1841), O Homem da Mascara Negra de Mendes Leal (1843), Rei ou Impostor? de Francisco Maria Bordalo (1847), Agostinho de Ceuta de Camilo Castelo Branco (1847), $O$ Grão Mestre d'Aviz de João Xavier Pereira da Silva (1854) e Alvaro da Cunha ou o Cavalleiro de Alcacerquibir de João Ferreira da Cruz (1855). ${ }^{4}$

A sucessão dos quadros recobre os episódios fundamentais da intriga romanesca, incluindo o regresso do cruzado, sob disfarce, à morada paterna, o torneio de Ashby, a captura do judeu por Front-de-Bœuf, o assalto ao castelo, o surgimento do rei Ricardo, o julgamento de Bois-Guilbert e o enlace de Ivanhoe com Rowena. Mas, decerto em parte por fazer concessões necessárias à exequibilidade cénica, omite diversas personagens, e dessa omissão resultam lacunas que prejudicam o fio do enredo. Desde logo, desaparecendo Locksley, não se compreende como aparece o Cavaleiro Negro a comandar o assalto a Torquilstone.

Mais, no plano da composição das personagens assinalam-se aspectos significativos. Por um lado, os nomes são aportuguesados, passando "Maurice" a "Mauricio", "Conrade" a "Conrado" e "Reginald Front-de-Bœuf" a "Reginaldo Cabeça-de-Boi". Acusará o texto preocupações com a eufonia ou a dizibilidade, mas estas não explicam que a "Rowena" de Scott se torne "Rowira", nem que "Rebecca" passe a "Sara"; e formas como "Brians" (por "Brian”), "de Barcy" (por “de Bracy”) e "Gruth” (por “Gurth”) parecem meras corruptelas. ${ }^{5}$ Por outro lado, a peça acentua o carácter maléfico da sua galeria de pérfidos, retirando-lhes ou pelo menos diminuindo-lhes a dignidade heróica e fazendo, ao invés, ressaltar a sua mesquinhez. No Quadro VII, “O Princepe e o Romeiro” (o romeiro é aqui Ricardo), João chega a fazer o juramento de investidura régia, e chega aliás a autorizar o assassínio de seu irmão, incidentes que Hogan adicionou ao enredo de Scott. A galhardia de Bois-Guilbert, bem recortada no romance original, esbate-se quando ele foge do castelo sitiado, escapando à obrigação e ao risco de participar na sua defesa. De resto, Bois-Guilbert - na narrativa de Scott, o verdadeiro contra-herói do protagonista - é despromovido por Hogan ao estatuto 
de figura secundária, só adquirindo destaque no Quadro VIII, “O Julgamento”, pois no início do drama não é ele mas de Barcy / de Bracy quem se abriga em casa de Cedric.

Acresce que, por motivos não explicados, tanto de Barcy como Cabeça-de-Boi são cavaleiros templários, quando na história original apenas Bois-Guilbert o é - e neste ponto podem vislumbrar-se sintonias, não sabemos se deliberadas, entre o drama de Hogan e certas intencionalidades ideológicas perceptíveis no romance histórico português seu contemporâneo. O Arco de Sant'Ana reporta-se, nas palavras do prefácio da primeira edição, à "mais perigosa e perniciosa de todas as oligarquias, a eclesiástica", subordinando toda a narrativa à afirmação: "Hoje é util e proveitoso lembrar como os povos e os reis se uniram para debelar a aristocracia sacerdotal e feudal" (Garrett 2004: 56, 59). A obra de Garrett constitui - naturalmente entre outras coisas - um libelo contra eventuais derivas ultramontanas. Por seu turno, o romance de Herculano, em especial na figura do presbítero de Carteia, comporta uma reflexão crítica - adversa - acerca do celibato eclesiástico. 0 questionamento do celibato, aliás, efectua-se, e em registo muito extremado, pela voz de Bois-Guilbert em Scott, e não é impossível que o interesse despertado entre nós por Ivanhoe tenha capitalizado com essa incidência temática. ${ }^{6}$

Onde todavia a peça de Hogan diverge, quer do romance de Scott, quer dos émulos portugueses do ficcionista britânico, é no tratamento dado à figura do judeu. Contrariando os estereótipos antissemitas, Scott procede a uma bem-sucedida humanização dos judeus, que, mau grado a violência e os insultos de que são alvo, surgem como adjuvantes de Ivanhoe e, logo, da causa legitimista dos partidários do rei Ricardo. Num plano complementar, menos imediatamente político, a beleza e a compaixão de Rebecca, e bem assim o sofrimento físico de Isaac e o seu desvelo pela filha, concitam a empatia do leitor. Desta forma, a representação dos judeus concorre para a perspectiva de conciliação interétnica e inter-religiosa que anima o romance de Scott e que encontra paralelismo em textos portugueses como o "romance-crónica" Os Tripeiros de Coelho Lousada, em que as personagens mais positivamente valorizadas são aquelas que se dispõem a atravessar as linhas de fronteira entre cristãos, judeus e mouros, num cenário em que coexistem ainda comunidades de arménios, gregos, flamengos e genoveses. No drama de Hogan, pelo 
contrário, o preconceito antissemita é bem palpável, patente no horror com que Ivanhoe encara o seu equívoco ao confundir Sara, a "tentação do inferno", com uma "[m]ulher devina" no Quadro IV (Hogan 1849: 50, 47), intitulado justamente “A Tentação”, e transparecendo na personagem do velho agiota tomado de uma espécie de concupiscência do metal nos Quadros II e V. Essa volúpia que sobrepesa ao amor pela filha é tão vil que quase somos levados a pensar que a tortura de Ysaak no Quadro V é merecida, a despeito de esse segmento da peça se intitular "Horror do Feudalismo".

Entretanto, the plot thickens, como soi dizer-se. Certo desvio melodramático decorre de um caldo de cultura que faz inserir na matéria scottiana detalhes que não se detectam no romance. Em Os Dois Renegados de Mendes Leal (1839), "tentação do Inferno" é como o judeu apelida o frade que, estando ele na enxovia do Santo Ofício, o quer persuadir a apostasiar da sua religião, pois a conversão ao Cristianismo garantir-lhe-ia a liberdade e com esta poderia voltar a ver a amada cristã (Acto III, cena III; Rebello 2007: 278).7 É uma curiosa correspondência de fraseado, quando os dados da emoção e da identidade se mostram redistribuídos no cotejo das duas histórias. E outrossim, enquanto a Rowena de Scott nunca desfalece, a Rowira de Hogan desmaia por duas vezes. Nisto é acompanhada por outras figuras (e não apenas femininas) do drama histórico português: a duquesa de Bragança, D. Isabel d'Alencastro, em Lopo de Figueiredo ou a Corte de D. João II, de Inácio Pizarro de Morais Sarmento (1839); a infanta D. Beatriz em Um Auto de Gil Vicente (1838) e Alda em O Alfageme de Santarém (1842), de Garrett; Branca em O Homem da Mascara Negra de Mendes Leal. Não consta igualmente da narrativa do autor escocês o tema dos dias aziagos. A acção da peça de Hogan abre numa noite tempestuosa que é o aniversário da partida de Ivanhoe, recordado por Rowira com pressentimentos ansiosos, como se contivesse a noite "terrivel e medonha” um “aviso do Ceo" (Acto I, quadro I, cena I; Hogan 1849: 11). Garrett carrega de pressentimentos funestos o seu Frei Luís de Sousa (estreado em 1843, publicado em 1844). A angústia de D. Madalena de Vilhena, confessada a Frei Jorge, prende-se com uma extraordinária convergência de aniversários:

Hoje... hoje! Pois hoje é o dia da minha vida que mais tenho receado... que ainda temo que não acabe 
sem muito grande desgraça... É um dia fatal para mim: faz hoje anos que... que casei a primeira vez; faz anos que se perdeu el-rei D. Sebastião; faz anos também que... vi pela primeira vez a Manuel de Sousa. (Acto II, cena X; Garrett 1994: 168)

É o dia da chegada do Romeiro. E também este diz que se cumpre nesse dia um ano desde que foi libertado (cf. Acto II, cena XIV; idem: 179-180).

Singular interesse tem o drama de António Joaquim da Silva Abranches 0 Captivo de Fez (1841), por nele ter intervindo Garrett, fosse retocando-o, fosse participando na atribuição do prémio do Conservatório em 1840, fosse ainda servindo de ensaiador, e por subjazer esse texto à composição de Frei Luís de Sousa. O Captivo de Fez conta a história de D. Fernando de Castro, perdido na expedição a Tânger, havendo notícia de que está morto. Bígama involuntária, sua mulher casou entretanto com o conde de Távora, que, discrepando de toda a benevolência e dignidade, vem a garantir o encarceramento de D. Fernando e a ordenar que ele seja envenenado. Perante D. Fernando, o Padre Francisco Cabral solta um horrorizado: "Quem és tu?!" (Acto II, cena V; Rebello 2007: 362) - mas a réplica "Ninguém" é selo garrettiano que não existe aqui, como o é a presença da filha Maria no drama de Manuel de Sousa Coutinho. Na obra de Silva Abranches, D. Leonor morre (sem causa aparente, ou seja, morre de melindre moral), e os dois maridos, que querem bater-se em duelo, acordam em partir para guerrear em Alcácer-Quibir.

Estimulante é ainda observar um elemento de intriga secundária em $O$ Captivo de Fez. Deslocando-se a Portugal, o judeu Jacob queixa-se de ter perdido a honra de sua filha, Raquel, depois de ter generosamente auxiliado um cristão em Fez; e pretende agora vingar-se

de um português traiçoeiro e ingrato que pagou os benefícios que lhe fiz com me roubar toda a minha felicidade! Salvei-o para me perder!... A minha pátria, a minha família, a minha fortuna, tudo, tudo possuía com minha filha, as delícias, o amparo da minha velhice; mas foi enganada pela serpente do homem que a persuadiu que a amava, e era um falso! (Acto II, cena IV; Rebello 2007: 356) ${ }^{8}$

Ora, em O Arco de Sant'Ana, a história dos judeus Abraão Zacuto e Ester, estigmatizada esta, na velhice, como a bruxa de Gaia, tem parecenças com a de Jacob e 
Raquel (cf. Garrett 2004: 259-267), o que confere probabilidade a que tenha o drama de Silva Abranches um significado para o entendimento dos processos criativos garrettianos que extravasa do caso específico de Frei Luís de Sousa. A suspeita sai reforçada quando verificamos que o período de composição da tragédia se enxertou no ciclo de redacção de $O$ Arco de Sant'Ana, tendo-o interrompido e decerto contribuído para que o primeiro volume do romance fosse publicado apenas em 1845 e o segundo em 1851 (com data do ano anterior). ${ }^{9}$

Na conjuntura sobre a qual nos debruçamos, a contiguidade de romance original e romance traduzido - quase diríamos, a sua continuidade - torna-se por demais evidente se atentarmos no caso equívoco de A Mão do Finado (1853), romance de A. P. Hogan que, enquanto continuação de Le Comte de Monte-Cristo, passou para cima de século por obra do próprio Dumas, havendo reedição da editora Lello \& Irmão, do Porto, com data de 1974 - e existindo uma outra da Editorial Minerva (Lisboa, sem data) que, consolidando o insólito engano ou embuste, indica um tal M. J. Dias como tradutor. E comprova ainda a recíproca imbricação das duas vertentes da escrita mencionadas um outro romance de Hogan, Marco Tullio ou $O$ Agente dos Jesuitas, também publicado em 1853, que muito visivelmente abona o nosso argumento. A trama situa-se nos anos finais do reinado de D. Sebastião e nos lustros subsequentes ao desaparecimento do monarca português na planície de Alcácer-Quibir, numa campanha magrebina a que o incitam conspiradores a soldo de Filipe II de Espanha. 0 enredo depende, em parte, de um jogo de traições e identidades obscuras. Pretende uma facção que Marco Túlio, sósia e meio-irmão bastardo de D. Sebastião, é de facto o seu irmão gémeo e, porque primogénito, rei de direito. D. Sebastião de nada sabe e de nada desconfia, acolhendo assim como amigo íntimo aquele que para si constitui o maior perigo. Neste painel em que a honorabilidade se mescla com a perfídia, os vestígios de uma leitura de Ivanhoe são vários e plausíveis. Como seu pai, o príncipe D. João, o protagonista traja de negro. 0 reino representa-se sequestrado pela tirania dos poderosos, neste caso pela iniquidade do Tribunal do Santo Ofício e dos padres da Companhia de Jesus. A história é pontuada pelo relato de ofensas contra judeus, surgindo, em especial, referências aos abusos sofridos por velhos usurários e suas filhas, incluindo serem supliciados em autos- 
de-fé (cf. Hogan 1861: I, 122-125; II, 121-130). Depois da batalha em África, D. Sebastião, ferido, vê-se entregue aos cuidados de uma jovem moura, que dele se apaixona (cf. idem: IV, 19-25).

Ao mesmo tempo, Marco Tullio remete para dois outros romances históricos que o público português já tivera oportunidade de conhecer em tradução, se acaso os não lera no original. 0 enamoramento entre o protagonista e a sua futura esposa, Bela, inicia-se com um entoar de canções, de janela para janela, acompanhadas por bandolim (cf. idem: I, 58-60, 6768, 97-100, 109-113). Em Quentin Durward, Scott concebe uma circunstância análoga entre o herói e Isabelle, condessa de Croye, envolvendo canto e alaúde. Perto do final de Marco Tullio, e como derradeiro passo na senda de descredibilizar D. Sebastião, o protagonista sujeita-se a um auto-de-fé no qual se expõe a um burlesco onde a ralé o aplaude como "Rei dos Tolos" (cf. idem: IV, 80-84). A circunstância recorda o modo como Quasimodo é festejado pelo povo em Notre-Dame de Paris. Quentin Durward teve tradução portuguesa em 1838, o romance de Victor Hugo em 1841.10

4.

Muito mais haverá a descobrir, com certeza, neste caminho de aproximações e contrastes que pode ser gizado em torno da fortuna de Ivanhoe e do modo como a obra intersecciona a ficção narrativa e dramática de meados do século XIX português, de cunho histórico ou outro. Eximindo-nos, agora, à abordagem genérica (no duplo sentido desta palavra), pretendemos terminar o presente estudo com uma conjectura respeitante a Garrett e ao seu Frei Luís de Sousa, obra à qual o autor aponta, precisamente, a irregularidade de não se adequar às concepções de género, pois se na forma (mormente por ser em prosa) pertence à modesta categoria do "drama", "pela índole há-de ficar pertencendo sempre ao antigo género trágico" (Garrett 1994: 63). O reconhecimento deste hibridismo encontra-se na memória lida “Ao Conservatório Real” e que Garrett colocou em posição prefacial à peça.

Para aportar à desditosa história de D. João de Portugal e Manuel de Sousa Coutinho, experimentemos olhar para a trama de Ivanhoe por um prisma focado em Ricardo Coraçãode-Leão: é a história de um homem (um monarca) desaparecido, suposto morto por alguns, 
desejado morto por outros, cuja ausência do reino dá azo a desmandos e desgovernos, e a cujo ansiado regresso se agrega uma esperança redentora, por parte dos grupos e individualidades que o leitor é levado a prezar em maior grau. Abstraída à especificidade que a situa em coordenadas históricas inglesas da Idade Média tardia e reduzida a este esqueleto, a fábula de Ivanhoe assemelha-se, de modo flagrante, ao mito nostálgico e messiânico do Sebastianismo. ${ }^{11}$

Que esta relação não é especiosa ou forçada sugere-o o facto de Hogan ter encontrado oportunidade para fazer ecoar o drama de Garrett no seu. No plano da realização textual, as afinidades entre o imaginário de Ivanhoe e o imaginário sebástico concretizam-se na parte final do Quadro II do texto de Hogan - o único quadro que não tem título -, onde se encena um episódio largamente engendrado pela inventiva do adaptador. No romance, Rowena só reconhece Ivanhoe depois da sua vitória na liça de Ashby-de-laZouche. No drama, ao invés, Rowira procura o romeiro para pedir notícias de Ivanhoe e acaba por reconhecê-lo. 0 episódio situa-se no castelo de Cedric, logo na primeira noite da acção:

ROWIRA.

Santo Deos! Romeiro.... ah.... perdoa-me.... isto, é alienação minha; mas

pareceu-me ouvir a sua voz..... as suas expressões, dictadas pelo ardente amor

que o arrebatava.... o teu rosto.... as tuas feições....

PEREGRINO.

São-nas de um pobre e miseravel Romeiro....

ROWIRA.

Como o coração me bate!.... como estranha força me conduz a teu peito!..

Oh!... tu.... tu quem és!?...

PEREGRINO.

Ninguem.... (desviando-se)

ROWIRA.

Ninguem serás para o mundo; mas para mim, és muito.... és o unico esteio que me prende ao peito o coração.... ao coração a vida.... (descobrindo-lhe rapidamente o rosto) Meu Deos...... é elle!.... Felicidade...... gloria..... tudo perdeu!.... É elle!.... é elle!...... (Cahe desmaiada, Ivanhoe a ampara pouco a роисо) 
IVANHOE.

E tu, desgraçado: cumpre agora, a vontade do Ceo!

(Cahe o panno. Finaliza o 2.ำ quadro e 1.ํoacto.[D]

(Acto I, quadro II, cena [VI]; Hogan 1849: 30) ${ }^{12}$

"Ninguém": é um lance garrettiano aposto à matéria achada em Scott, a um tempo denotando a canonicidade rapidamente granjeada pela tragédia de Garrett (cujo relevo se divisa mesmo fora dos limites do drama trágico) e evidenciando a diferença entre a concisão de Garrett e o arroubo melodramático de Hogan, incapaz de absorver o magistério de economia de meios do primeiro Inspector-Geral dos Teatros (cf. Garrett 1994: 185). Esta dupla relevância da obra de Garrett como que se confirma no dramalhão camiliano $O$ Marquês de Torres Novas, publicado no mesmo ano que o Ivanhoe de Hogan, e que, sobre uma ideia tirada dos Anais de D. João III de Frei Luís de Sousa, conta a história de um homem que volta do degredo em África para se deparar com a mulher casada com outro. 0 texto garrettiano ressoa no momento em que o regressado, convertido em assassino (a pena do melodrama alcança tintas mais carregadas em Camilo, e também Camilo é mais prolixo do que Garrett), se torna objecto da estupefacção dos que o contemplam:

\section{MARQUÊS}

Foi à luz baça duma lâmpada... "Este chão será o tálamo de Maria de Noronha... aqui está o meu sepulcro!..." Disse-o Ezequiel... e Maria de Noronha... matei-a...

FREI GUTERRES

Irmão! em nome de Jesus Cristo, dizei-me quem é este homem?!

AFONSECA

Ninguém, Senhor!... é um doudo!... coitadinho!... é um doudo!...

(Castelo Branco 1982-2002: IX, 527) ${ }^{13}$

Falámos de um lance garrettiano aposto a Scott. Ora, seguindo o caminho inverso, não se descortinará em Frei Luís de Sousa uma filiação scottiana, porventura intuída por Hogan e denunciada no passo em que se desvenda a identidade desse romeiro que é "ninguém" e que "tudo perdeu" - que perdeu nome, posição e casamento - e a quem falta 
um rei, de quem de certo modo faz as vezes? Pois D. João de Portugal (que bem serviu a Garrett neste caso a desdenhada arte de "assentar nomes"! [Garrett 1994: 70]) - D. João de Portugal é a presença possível do ausente D. Sebastião, tal como Ivanhoe é um avatar do encoberto rei Ricardo. ${ }^{14}$

Podemos pôr a questão de outras maneiras ainda. Vindicando a liberdade de cultor do drama, que não da historiografia, declara Garrett, na memória "Ao Conservatório Real”, não sacrificar às musas de Heródoto mas às de Homero (cf. idem: 69-70); será que, em ministério secreto, sacrifica às musas de Scott também, não somente em $O$ Arco de Sant'Ana, como assinalámos acima, mas no próprio Frei Luís de Sousa? Terá Frei Luís de Sousa sido informado pelo Ivanhoe de Scott, esse "escriptor mais nacional de que nunca houve memoria", como o qualificou Garrett nas páginas d'O Chronista em 1827?15

Já Andrée Crabbé Rocha considerou suspeito o emaranhado de fontes evocadas na memória ao Conservatório (para discussão e documentação das presumíveis fontes, cf. Rocha 1954: 152-165, 243-261). Garrett menciona notícias biográficas relativas a Frei Luís de Sousa, O Captivo de Fez de Silva Abranches, um romance de Ferdinand Denis (Luiz de Souza, publicado em Paris em 1835), um espectáculo de teatro ambulante com actores castelhanos a que assistiu em data já longínqua (cf. Garrett 1994: 57, 67-70). Pergunta-se aquela estudiosa: "Não haverá aqui fartura demais?" (Rocha 1954: 153). Talvez fartura inverosímil, de facto, que servirá para dissimular o que não se quer dizer, tanto mais que o autor nem sempre, noutros lugares, é inocente de plágio. ${ }^{16}$ Talvez a colagem de Hogan à peça de Garrett, intencionalmente ou não, ofereça a chave do cofre onde se encontra encerrada uma fonte de Frei Luís de Sousa que importa averiguar. Talvez o gesto de admiração do discípulo traia o mestre, deixando entrever, não diríamos que o mestre do mestre, mas, no romance de Scott, pelo menos uma fonte mais, uma influência, ou tãosomente - se preferirmos uma tese menos arriscada - uma instanciação pertinente do mesmo imaginário.

As similitudes, permitimo-nos frisar, são muito mais que acidentais. Exploradas nas suas estruturas e intencionalidades interpelativas profundas, comportam estas obras (a de Scott, a de Garrett, a de Hogan) uma questionação in limine daquele heroísmo entre o 
generoso e o insensato que acalenta o espírito de cruzada. ${ }^{17}$ Exprimem a necessidade de esse heroísmo ter sido e a necessidade de que ele não volte, mas que, pelo contrário, regresse um rei que, por ter exorcizado o impulso da partida, possa constituir-se em agente de salvação nacional aqui mesmo onde é preciso, e não num longe mais ou menos mirífico, mais ou menos fatal.

\section{Anexo}

\section{Anagnorisis: "Romeiro, Romeiro! quem és tu?"}

No corpo do nosso artigo, fizemos notar não apenas que o célebre momento da peripécia em Frei Luís de Sousa (Acto II, cena XV, aliás ecoando em réplicas trocadas entre Telmo e o Romeiro na cena V do Acto seguinte; cf. Garrett 1994: 185, 206) apresenta correspondências com um passo do Ivanhoe de Alfredo Possolo Hogan e com outro de Camilo em $O$ Marquês de Torres Novas, mas também que no confronto desses vários textos se pode reconhecer a arte de Garrett, que pela concisão do verbo atinge uma acutilância de efeito dramático sem par no contexto formado pelas obras mencionadas. Aí, os elementos fundamentais são o sonoro "Ninguém" do regressado e o desfalecimento do interlocutor, que cai prostrado sem ser capaz de pronunciar qualquer palavra.

Pretendemos agora acrescentar alguns dados, para demonstrar que repercute mais largamente ainda, no teatro da época, o encadeamento daqueles traços, aos quais pode ou não agregar-se um lugar de cena incorporando uma galeria de retratos escolhidos com clara intencionalidade (no caso de Frei Luís de Sousa, as imagens mais conspícuas são as de D. João de Portugal, de el-rei D. Sebastião e de Camões, na casa que fora do primeiro dos três; veja-se a didascália do início do Acto II, idem: 132).

No alinhamento destes exemplos confirma-se a excepcionalidade de Garrett, que compreendeu a superior consequência daquele silêncio, daquele emudecimento de Frei Jorge que antecede o desmaio. Constata-se que a contracção dramática alcançada por Garrett proporciona uma intensidade que nem é ferida pela deflação patética de que padece 
o "coitadinho" de Camilo nem resvala para um prolongamento palavroso do impacto da revelação da identidade desse redivivo que é D. João de Portugal.

Há vantagem em registar, desde logo, que o tema do regresso de um homem desaparecido e julgado morto está longe de ter sido introduzido nos palcos portugueses por Garrett, pois remonta, pelo menos, a Fayel, tragédia de François de Baculard d'Arnaud vertida em 1794 por João Baptista Gomes Júnior e da qual pudemos consultar o texto da reedição de $1803 .{ }^{18}$ Trata-se de uma história de zelos e pundonores extremos, sobre um cavaleiro francês que, retornado das Cruzadas, se descreve ferino:

Que nutro neste peito hum monstro horrivel:

Sou hum barbaro, hum tigre, que esfaimado

Rugindo furioso despedaça

A infeliz preza nas cruentas garras.

(Acto I, cena III; [D’Arnaud] 1803: 16)

Não deixa Fayel de ter razões para a sua ira. Gabriela, a esposa, está dividida entre o dever que lhe compete prestar ao marido e a paixão por outro homem, de quem ficou noiva. 0 enredo é terrífico, com um tom exacerbado e um final bem distante, quer do desfecho feliz do Ivanhoe de Hogan, quer da tristeza aliada à resignação cristã de Frei Luís de Sousa. A peça de Mr d'Arnaud termina com o coração do amado a ser entregue a Gabriela, arrancado pelo marido, que a apunhala também - e com Fayel a suicidar-se, declarando que não pode viver sem ela.

Quatro décadas mais tarde, no ano em que Garrett, em representação semiprivada, fez subir à cena Frei Luís de Sousa, mas inscrevendo ao centro da folha de rosto a data da sua estreia em 1840, publicou José da Silva Mendes Leal Júnior O Homem da Mascara Negra. O drama versa o regresso de um nobre que se presumia morto, no dealbar da dominação filipina em Portugal. António Baracho teria desaparecido na Índia, para ondem partira por desgosto amoroso, e reaparece como um "incógnito" embuçado e trajando de escuro, ardendo de uma sede de vingança que o torna um assassino inclemente. "[F]az hoje dois annos", diz o embuçado (e Hogan também explora o tema dos aniversários infaustos, como 
vimos), que o conde D. Álvaro viu pela primeira vez e se apaixonou por uma mulher que lhe veio a entregar a honra, Branca, irmã de Baracho (Acto I, cena V; Leal Júnior 1843: 13). D. Álvaro enamorou-se depois de outra mulher. A desmedida tonalidade macabra da peça é bem sensível no desafio lançado pelo "incógnito" ao conde: "Vem, altivo Conde, a hora solemne soou (...). Vem, vem... Vou emfim revolver-me no teu sangue, saciar-me no espectaculo das tuas ancias, beber uma alegria em cada um dos teus ultimos arrancos" (Acto II, cena IV; idem: 45).

Por último, data de 1855 o drama histórico de João Ferreira da Cruz Alvaro da Cunha ou o Cavalleiro de Alcacerquibir, que, como o texto de Mendes Leal, foi já atrás referido. Tal como naquele, aparece em Alvaro da Cunha um embuçado, que não é senão a personagem a que alude o título, ressurgida em Portugal para se vingar, depois de um suposto assassinato nas masmorras de África. 0 momento capital, para os nossos intentos, situa-se no fecho do Acto II:

\section{FERNANDO.}

(...) Quem... quem és tu que tão ousadamente me insultas? (Leva as mãos aos copos da espada).

EMBUÇADO. (Arrojando a capa e fazendo o mesmo).

Sou um homem que nunca buscou assassinar outro homem por meio de traição. Sou um homem que combateu pela patria, e que nunca virou costas ao inimigo, nem nos conflictos mais arriscados... sou... ainda não sabes? não me conheces ainda?!...

D. FERNANDO. (Tremulo e horrorisado).

É impossivel!... Quem és? falla!... explica-te!... acaba!...

EMBUÇADO.

Sou aquelle, cuja espada se encontrou já uma vez com a tua; sou aquelle que foi prisioneiro dos Infieis, e que sem duvida julgavas morto no captiveiro... sou aquelle aquem Deos conservou a vida para que um dia entregasse á justiça dos homens um perverso que só tem vivido de insidias... sou... sou o propria [sic] Alvaro da Cunha, o Cavalleiro de Alcacerquibir! (Levanta a viseira, e crusa os braços, fazendo um gesto ameaçador com a cabeça).

D. FERNANDO. (Que tem ouvido com grande agitação as palavras do

Embuçado, ao reconhecer Alvaro, recúa espavorido).

Ah!... (Cahe redondamente). 
Aqui, ao contrário do que sucede no texto de Hogan, não é tanto a personagem surpreendida pela revelação que se espraia em palavras: é o próprio desaparecido que ventila prolongadamente a sua indignação e a sua fúria, em vez de proferir um sucinto "Ninguém". Vale ainda citar, para os nossos propósitos, que na didascália de abertura do Acto IV se lê: "Um gabinete. Ao fundo o retrato de D. Affonso Henriques, D. Sebastião e Luiz de Camões" (idem: 95).

Os textos de Hogan, Camilo e Ferreira da Cruz reflectem uma assimilação do modelo garrettiano - uma assimilação necessariamente imperfeita, porque se fosse perfeita era cópia, mas da qual resulta a evidência da inferioridade estético-dramática desses epígonos. Tanto mais que só em Garrett se encontra uma tragédia de destino, só na sua obra é a íntima nobreza das personagens impecavelmente preservada, porque só ali se dá, verdadeiramente, uma tragédia sem culpa; nas obras restantes, se há infortúnio à mistura, sobressai acima de tudo a sanha assassina, primeiro, o rancor vingativo, depois, e de uma maneira geral a ferocidade dos caracteres e a desonra das condutas. Também por aí, por uma estatura de temperamentos que se ajusta à altura do acabamento formal, se distingue o drama de Garrett. 


\section{Bibliografia}

Bastos da Silva, Jorge (2014), "Ivanhoe e o Romance Histórico Português de Oitocentos", in Jorge Bastos da Silva, Tradução e Cultura Literária. Ensaios sobre a Presença de Autores Estrangeiros em Portugal, Porto, Instituto de Literatura Comparada Margarida Losa / Edições Afrontamento, 171-190.

-- (2015), o Discurso sobre a Tradução na Literatura Portuguesa (Classicismo e Romantismo) - Antologia, Porto, Instituto de Literatura Comparada Margarida Losa / Edições Afrontamento.

-- (2016), "Scott's Ivanhoe in Portuguese Romanticism: The Case of A. P. Hogan's Stage Adaptation", in Aniela Korzeniowska and Izabela Szymańska (eds.), Scottish Culture: Dialogue and Self-Expression, Warszawa, Semper, 115-124.

Castelo Branco, Camilo (1982-2002), Obras Completas, dir. Justino Mendes de Almeida, Porto, Lello \& Irmão [depois Lello Editores], 18 vols.

Cidade, Hernani (1975), Lições de Cultura e Literatura Portuguesas, 6. a ed., s.l., Coimbra Editora, 2 vols.

Cruz, Duarte Ivo (2004), "Dramatização de um Mito: D. Sebastião, o Sebastianismo, os Falsos D. Sebastião no Teatro Português", in AA. VV., Colóquio O Sebastianismo. Política, Doutrina e Mito (Sécs. XVI-XIX), Lisboa, Academia Portuguesa da História / Edições Colibri, 277-327.

Cruz, João Ferreira da (1855), Alvaro da Cunha ou o Cavalleiro de Alcacerquibir, Lisboa, Typ. Lisbonense de Aguiar Vianna.

[D’Arnaud, François] (1803), Fayél: Tragedia de M.r d'Arnaud, traduzida em verso portuguez por Joaõ Baptista Gomes, 2. ${ }^{a}$ ed., Porto, Na Officina de Antonio Alvares Ribeiro.

[Garrett, Almeida] (1827), o Chronista, Lisboa.

Garrett, Almeida (1994), Frei Luís de Sousa, edição de Maria João Brilhante, 3.ㄹ ed., Lisboa, 
Editorial Comunicação.

-- (2004), O Arco de Sant'Ana. Crónica Portuense, ed. Maria Helena Santana, Lisboa, Imprensa Nacional - Casa da Moeda.

-- (2015), Fragmentos Romanescos, ed. Ofélia Paiva Monteiro e Maria Helena Santana, Lisboa, Imprensa Nacional - Casa da Moeda.

Hogan, Alfredo (1849), Ivanhoe. Drama em Cinco Actos e Nove Quadros extrahido do romance de Sir Walter Scott Ivanhoe ou a Volta do Cruzado, Lisboa, Typ. da Rua da Bica de Duarte Bello.

-- (1861), Marco Tullio ou O Agente dos Jesuitas (1568-1600), [2. ${ }^{\text {a }}$ ed.], Lisboa, Na Typographia de L. Correa da Cunha, 4 vols.

Leal Júnior, J. S. M. (1843), O Homem da Mascara Negra, Lisboa, Na Imprensa Nacional.

Lewis, Matthew (1995), The Monk, ed. Howard Anderson, intr. Emma McEvoy, Oxford, Oxford University Press.

Lourenço, Eduardo (1988), “Da Literatura como Interpretação de Portugal (De Garrett a Fernando Pessoa)", o Labirinto da Saudade. Psicanálise Mítica do Destino Português, 3. Lisboa, Publicações Dom Quixote, 79-118.

Mendonça, A. P. Lopes de (1849), Affronta por Affronta. (...) Casar ou Metter Freira, Lisboa, Na Impressão da Epoca.

O Panorama (1837-68), Lisboa.

Rebello, Luís Francisco (2007), Teatro Romântico Português - O Drama Histórico, Lisboa, Imprensa Nacional - Casa da Moeda.

Rigney, Ann (2012), The Afterlives of Walter Scott: Memory on the Move, Oxford, Oxford University Press.

Rocha, Andrée Crabbé (1954), O Teatro de Garrett, 2.ㄹ ed., Coimbra, Coimbra Editora. Scott, Walter (1998), Ivanhoe, ed. Graham Tulloch, Edinburgh, Edinburgh University Press. 
Vasconcelos, Ana Isabel P. Teixeira de (2003), O Drama Histórico Português do Século XIX (1836-56), s.l., Fundação Calouste Gulbenkian / Fundação para a Ciência e a Tecnologia / Ministério da Ciência e do Ensino Superior.

Wilson, A. N. (2002), A Life of Walter Scott: The Laird of Abbotsford, London, Pimlico [1980].

Jorge Bastos da Silva é docente do Departamento de Estudos Anglo-Americanos da Faculdade de Letras da Universidade do Porto. As suas áreas de investigação principais são a Literatura e a Cultura Inglesas, a História Intelectual, os Estudos sobre a Utopia e os Estudos de Tradução e Recepção. É autor e organizador de diversas obras, entre elas: $O$ Discurso sobre a Tradução na Literatura Portuguesa (Classicismo e Romantismo) - Antologia (2015); Tradução e Cultura Literária. Ensaios sobre a Presença de Autores Estrangeiros em Portugal (2014); The Epistemology of Utopia: Rhetoric, Theory and Imagination (2013); A Instituição da Literatura. Horizonte Teórico e Filosófico da Cultura Literária no Limiar da Modernidade (2010); Vasco José de Aguiar, Utopista Português do Século XIX (2010); Shakespeare no Romantismo Português. Factos, Problemas, Interpretações (2005); Utopias de Cordel e Textos Afins. Uma Antologia (2004); O Véu do Templo. Contributo para uma Topologia Romântica (1999). 


\section{NOTAS}

${ }^{1}$ Há que dizer, obviamente, que alguns desses nomes, hoje considerados centrais, eram pouco conhecidos do grande público britânico à época (quando não eram motivo de escândalo ideológico e pessoal, e portanto percebidos de modo desfocado), e menos ainda do público leitor dos países continentais.

${ }^{2}$ Tomamos por referência a lição do texto de Scott apurada por Graham Tulloch (Scott 1998).

${ }^{3}$ Nunca um livro de Scott vendeu tanto (cf. Wilson 2002: 158), e o estudo das adaptações narrativas e dramáticas do romance, bem como das suas ressonâncias na esfera das artes visuais, encheria tomos (cf., por exemplo, Rigney 2012: 78-126).

${ }^{4}$ Da abordagem sinóptica realizada por Ana Isabel Vasconcelos (2003: 495-551) constam catorze dramas com esta característica - isto é, mais de metade dos títulos recenseados.

${ }^{5}$ Não foi tão longe André Joaquim Ramalho e Sousa na sua tradução do romance, publicada em 1838. Contudo, não deixou de verter o nome de um dos cavaleiros normandos por "Reginaldo Fronte-de-Boi".

${ }^{6}$ No texto de Hogan, o tema aflora também explicitamente. Diz Bois-Guilbert no decurso do julgamento: "Sou um homem: tenho um coração que palpita sob esta armadura de cavelleiro Templario: e se os labios proferiram votos insensatos, e contra a natureza, elle reprovou-os porque lhe não era dado deixar de sentir o que o seu creador lhe ordenou que sentisse" (Acto IV, quadro VIII, cena V; Hogan 1849: 88).

${ }^{7}$ Por comodidade, reportamo-nos, para o texto de Os Dois Renegados assim como de Um Auto de Gil Vicente de Garrett e de $O$ Captivo de Fez de Silva Abranches, à reedição de Luís Francisco Rebello no volume Teatro Romântico Português - O Drama Histórico (2007).

${ }^{8}$ Relevando para as figuras de Rebecca e Ulrica no Ivanhoe de Scott (a segunda das quais não é incluída na adaptação de Hogan), o tema da donzela seduzida ou violada - condições que tendem a confundir-se - não rareia no teatro do Romantismo luso, atingindo níveis de crueza e florilégio como os que se encontram no drama de António Pedro Lopes de Mendonça Affronta por Affronta, representado pela primeira vez em 1848. Aí diz D. Fernando, conde de Artamar, a Maria: "Fui eu que vim crestar as rosas do teu rosto com o meu halito devorador!... Arranquei-te a corôa de donzella, e não posso dar-te em troca o ramalhete de desposada!" (Acto I, cena II; Mendonça 1849: 4). Maria é uma mulher do povo seduzida e abandonada por um nobre, que para a conquistar se fingiu pobre e plebeu.

${ }^{9}$ O primeiro esboço de $O$ Arco de Sant'Ana tem data de Agosto de 1832, como é assinalado por Maria Helena Santana no aparato crítico da sua edição da obra (cf. Garrett 2004: 16, 36-37). O passo a que aludimos pertence aos Capítulos XXVII e XXVIII, que se inseriam no segundo volume do romance. Frei Luís de Sousa foi composto em 1843.

Já em 1838, em Um Auto de Gil Vicente, Garrett fizera Bernardim Ribeiro aparecer "de capa caída e chapéu de romeiro", como forma de se ocultar (Acto II, cena II; Rebello 2007: 124-125). E num fragmento que ficou 
inédito e do qual existe manuscrito com data de 1825, "A Excelente Senhora. Romance Histórico", o narrador autodiegético mencionara também as suas "vestes de romeiro" (Garrett 2015: 127).

10 Sobre a importância deste romance de Hugo para o romance histórico do Romantismo português, ver referências em Bastos da Silva 2014: 178-179, n. 10.

11 Para o estudo do tema sebástico no drama romântico português pode servir de guião a resenha feita por Duarte Ivo Cruz (2004: 286-290, 319-320, 324-325).

12 O duplo vocativo "Romeiro... Romeiro..." ocorre em falas de Rowira e de Ysaak (cf. Acto I, quadro II, cenas III e [VI]; Hogan 1849: 24, 28).

${ }^{13}$ A personagem Ezequiel, referida no excerto, é um judeu, mas um amaldiçoado moral como o marquês de Camilo, um seu duplo (também ele atraiçoado, e vingado pelo marquês por engano); muito distante, portanto, do Isaac do romance de Scott, mas não de todo indissociável do preconceito que encarna no judeu do drama de Hogan.

Para não perturbarmos certo equilíbrio da exposição, remetemos para um Anexo a referência a outros dados relativos à anagnorisis arquitectada sobre o motivo do regressado como "ninguém".

14 Para um outro interseccionamento ainda podemos basear-nos em palavras inspiradas, perscrutantes, de Eduardo Lourenço. De Frei Luís de Sousa diz este ensaísta: "O drama de Garrett é fundamentalmente a teatralização de Portugal como povo que só já tem ser imaginário (ou mesmo fantasmático) - realidade indecisa, incerta do seu perfil e lugar na História, objecto de saudades impotentes ou pressentimentos trágicos" (Lourenço 1988: 85). Se os cruzamentos que apontamos sugerem proximidades entre o imaginário míticopolítico construído em torno de Ricardo I de Inglaterra e a lenda de D. Sebastião de Portugal, a leitura de Eduardo Lourenço permite lobrigar que a novelística de Scott, seja no caso de Ivanhoe, seja no de Waverley e de outros romances de temática escocesa, representa uma Escócia (mesmo quando esta se encontra ostensivamente ausente) que é povo que só já tem ser imaginário, país objecto de saudades impotentes ou pressentimentos trágicos - cuja impotência e cuja tragicidade os romances se ocupam de esconjurar.

${ }^{15}$ Veja-se um artigo intitulado precisamente "Sir Walter Scott" ([Garrett] 1827: II, n. ․ 17, 87).

16 Andrée Rocha (1954: 153-154) menciona uma empresa de teor distinto do literário, um trabalho administrativo ou jurídico, mas é interessante atentar também em Catão e na carta em que Garrett se afadiga com a vexata quaestio da dívida que tem o seu drama para com o de Addison (cf. Bastos da Silva 2015: 9, 89101).

Duvida aquela estudiosa da existência da peça castelhana. Se tal peça houve, pode ter sido A Secreto Agravio, Secreta Venganza, de Calderón de la Barca, segundo Luís Francisco Rebello, que adita ser pertinente considerar também uma balada "que Herculano traduziu e que inspirou o poema narrativo de Castilho A Noite do Castelo (1836)" (Rebello 2007: 38). Trata-se da balada "Alonzo the Brave, and Fair Imogine", do romance 
gótico de Matthew Gregory Lewis The Monk, de 1795 ou 1796 (cf. Lewis 1995: 313-316), que teve tradução de Manuel Martins da Cunha, com intermediação francesa, em 1861.

${ }^{17}$ Em Marco Tullio ou O Agente dos Jesuitas, o avisado D. João de Mascarenhas adverte contra a passagem a África planeada por D. Sebastião ao abrigo de uma bula de cruzada: "Por ventura póde o chefe d'uma nação abandonar o seu povo, e largar de mão as redeas do governo, para correr pessoalmente ao combate n'umas terras longiquas $[\mathrm{sic}]$ ? Será isto acizado?! Será prudente que a real pessoa de vossa magestade vá arriscar-se contra os infieis, e expôr o estado á desordem necessaria, que lhe resultará faltando-lhe, por assim dizer a mola principal da sua machina politica? Deverá o senhor rei abandonar em mãos alheias os interesses d'este paiz, que aprouve a Deus nosso Seuhor [sic], confiar nas suas?" (Hogan 1861: III, 53-54).

${ }^{18}$ Chamou-nos a atenção para esta obra um estudo de Hernâni Cidade (cf. Cidade 1975: II, 373-374). 